\title{
Changes in Physically-Chemical Parameters of Latvian Cranberries During Storage
}

\author{
Karina Ruse*, Tatjana Rakcejeva, Lija Dukalska \\ Department of Food Technology, LLU \\ Fredijs Dimins \\ Department of Chemistry, LLU
}

\begin{abstract}
The main purpose of the present research was to investigate the changes in physical-chemical parameters of fresh Latvian cranberries during storage. Cranberry ('Steven', 'Bergman', 'Pilgrim', 'Early Black', and 'Ben Lear') fruit were collected at a processing plant in Kurzeme region, Latvia, in the first part of October 2010. For the experiments, also wild cranberries were collected in the bogs of the same region and at the same time. The berries were rinsed with tap water for $3 \pm 1 \mathrm{~min}$, then strained for $10 \pm 1$ min (mainly for visual cleanness), and afterwards stored in closed non-perforated polypropylene (PP) boxes in air ambiance and in glass jars in a cold boiled-water ambiance at $3 \pm 1{ }^{\circ} \mathrm{C}$. Quality parameters of the berries were tested each three months using standard methods: vitamin $\mathrm{C}$ content - by high-performance liquid chromatography (HPLC); organic acids - by HPLC; moisture - by oven-dry method; colour parameters - by device COLOR TEC PMC; pH - by potentiometric method; anthocyanin - by spectrophotometrical method; and phenolic compounds by HPLC. The shelf life of cranberries packaged in closed PP boxes in air ambiance was six months, but of cranberries packaged in glass jars in water ambiance - 12 months. The research showed that differences in moisture content, $\mathrm{pH}$ value, colour intensity, and anthocyanin content among the cranberry cultivars under different ambient conditions during storage were not significant. During 12 months of cranberry storage in glass jars in water ambiance, the content of vitamin $C$ decreased on average by $90 \%$, organic acids - by $54 \%$, and phenolic compounds - by $60 \%$. During six-month storage in closed PP boxes in air ambiance, the content of vitamin C decreased on average by $99 \%$, organic acids - by $30 \%$, and phenolic compounds - by $34 \%$.
\end{abstract}

Key words: Cranberries, vitamin $\mathrm{C}$, anthocyanin, organic acids, polyphenol content.

\section{Introduction}

The cranberry fruit is an excellent raw material for juice production, as it contains numerous antioxidants, including phenolic compounds, vitamin $\mathrm{C}$, minerals and many others nutrients. Compounds present in the fruits of the Vaccinium species are reported to play several roles in human health maintenance. Effective inhibition of urinary tract infections has been recently attributed to the presence of high molecular weight constituents, present in Vaccinium macrocarpon (cranberry) juices, which act as anti-adhesive agents preventing bacterial colonization. Health benefits, including reduced risks of cancer and cardiovascular disease, are believed to be due to the presence of various polyphenolic compounds, including anthocyanins, flavonols, and procyanidins (Caillet, Côté, Doyon, Sylvain, \& Lacroix, 2011b).

Epidemiologic studies within populations have indicated that a high dietary intake of vitamin $\mathrm{C}$ is associated with a decreased risk of cardiovascular disease and venous thromboembolism. Vitamin C is the main water soluble antioxidant in human plasma. The biologic mechanisms whereby vitamin $\mathrm{C}$ in fruits and vegetables may exert its protective effects are not entirely clear and are likely to be multiple. Vitamin C may protect against the development of ischemic heart disease by improving endothelial dysfunction and by reducing blood coagulability (Ellingsen, Seljeflot, Arnesen, \& Tonstad, 2009).

The sugar content in berries is counterbalanced by the presence of several predominant organic acids such as citric and malic acid, as well as phenolic acids that can impart bitter or astringent flavours that are responsible for the basic taste components. The compliment of organic and phenolic acids in berries is responsible for the titratable acidity of the fruit and is commonly measured as an overall index of fruit quality, whereas measurements of $\mathrm{pH}$ are often

\footnotetext{
* Corresponding author's email:

karinaruse@inbox.lv
}

(C) Latvia University of Agriculture (LLU) 2013 
poor indicators of fruit quality characteristics. High concentrations of organic acids in most fruits are also critical for fruit preservation, maintaining a low $\mathrm{pH}$ in processed fruit applications such as jams and jellies. Organic acids also help to stabilize ascorbic acid and are critical in fruit color by serving to stabilize anthocyanin and extend the shelf life of fresh and processed berries (Zhao, 2007).

Organic acids are important primary metabolites that contribute to berry growth and development. The organic acids malic and tartaric acid are the most abundant compounds contributing to the berry juice sweetness and acidity respectively. Their concentrations and/or ratios vary during the berry development and maturation stages. Organic acids are produced in both the leaves and berries and start accumulating in the berry at early stages of berry development. The accurate quantification of these metabolites in berries at the different stages of berry development is important to follow berry development and ripening, specifically when evaluating the impact of viticulture practice on berry characteristics and subsequent wine properties (Eyéghé-Bickong, Alexandersson, Gouws, Young, \& Vivier, 2012).

Fresh berries are highly perishable, and their quality and shelf life can be greatly affected by different pre- and post-harvest factors. The amount and extent of low and high temperatures during the growth and maturation period of raspberries and blackberries have a definite influence on the antioxidants, including anthocyanin, vitamin C, and total phenolic. Berries grown with lower light intensities and shorter day length have lower levels of sugars and antioxidants. A number of authors have noted that storage at low temperatures $\left(2{ }^{\circ} \mathrm{C}\right)$ positively affects the quality and shelf life of fruit, including berries (Ali, Svensson, Alsanius, \& Olsson, 2011).

Colour is an important factor in the consumer's choice of food products. It is one of the most important characteristics used to define the quality of food and has a decisive influence on the acceptance by the consumer (Hendry, \& Houghton, 1996). CIELab is a nonlinear transformation of XYZ into coordinates $\mathrm{L}^{*}$, $a^{*}$, and $b^{*}$, and it is used for the colour measurement interpretation (Hoffmann, 2008).

Many small fruit phenolic compounds are good sources of natural antioxidants and have inhibitory effects on mutagenesis and carcinogenesis. During the past decades, extensive analytical research has been carried out on the separation and determination of phenolic constituents in various fresh fruit products and environmental samples. The unique antibacterial activities of cranberry implicate that cranberry may possess a flavonoid and phenolic composition that is very different from that of other kinds of fruits. An efficient separation and quantitation method is essential for understanding the components of flavonoid and phenolic antioxidants in cranberry, as well as their health benefits. Phenolic compounds are not temperature resistant; therefore treatment at elevated temperatures will negatively influence polyphenol compound activity (Chen, Zuo, \& Deng, 2001).

Anthocyanin pigments are responsible for the red-purple to blue colours of many fruits, vegetables, and grains. They are water soluble and are used as natural food colorants for a long time and therefore are regarded as safe (Potter \& Hotchkiss, 1997). The antioxidative activity of anthocyanin has been recently considered to be responsible for the protection against chronic diseases in vivo (De Rosso \& Mercadante, 2007; Camire, Dougherty, \& Briggs, 2007). Therefore it is desirable to stabilise anthocyanin in food systems and to enrich foods with these pigments. A limiting factor for the incorporation of anthocyanin in foods is the low stability of these pigments, which is influenced by several factors as, for example, $\mathrm{pH}$, oxygen, enzymes, etc. (Jackman \& Smith, 1996).

In the scientific literature, data about the changes in the chemical composition of fresh cranberries stored at $3 \pm 2{ }^{\circ} \mathrm{C}$ in PP boxes in air ambiance and in glass jars in water ambiance were found to be insufficient. The aim of the present research was to investigate the changes in physical-chemical parameters of fresh Latvian cranberries during storage under traditional conditions.

\section{Materials and Methods}

Cranberry (Vaccinium macrocarpon Ait.) cv. 'Steven', 'Bergman', 'Pilgrim', 'Early Black' and 'Ben Lear' fruit were collected in Kurzeme region, Latvia, in the first part of October 2010. For the experiments, also wild cranberries were collected in the bogs of the same region and at the same time. The fruit were sorted by visual inspection into four ripeness stages: dark-red, light-red, blush, and white. Fruit showing rot, mechanical injury, disease, or flesh softness were discarded. Samples were immediately used for the experiments.

Berries were rinsed with tap water for $3 \pm 1$ min, then strained for $10 \pm 1 \mathrm{~min}$ 
mainly for visual cleanness, and afterwards stored in closed non-perforated PP boxes $\left(150^{\prime} 100^{\prime} 50 \mathrm{~mm}\right)$ in air ambiance and in glass jars in a cold boiled-water ambiance at $3 \pm 1{ }^{\circ} \mathrm{C}$ according to (Perkins-Veazie \& Collins, 2002; Reynoso \& Michelis, 1994) for 12 months. The quality parameters of berries were tested each three months using standard methods.

Vitamin C content was determined by the standard method LVS EN 14130:2003 "Foodstuffs - determination of vitamin C by HPLC". For vitamin $\mathrm{C}$ extraction from the analysed berry sample, metaphosphoric acid solution was used. The reducing solution was used for modification of dehydro-L(+)-ascorbic acid to $\mathrm{L}(+)$-ascorbic acid. Total L(+)-ascorbic acid content was determined using HPLC with UV spectrum at $265 \mathrm{~nm}$.

Organic acids were extracted with water using the method described by Hernandez, Lobo, \& Gonzalez (2009). A granulated 3-g sample was homogenised with $10 \mathrm{~mL}$ of distilled water, centrifuged for $10 \mathrm{~min}$, and filtered through a $0.45-\mathrm{mm}$ filter. The organic acids were detected using HPLC with UV detector at $280 \mathrm{~nm}$.

Moisture content was determined using ovendry method, where $3.00 \pm 0.01 \mathrm{~g}$ of berries were cut prior to drying at the oven-drier "Precisa XM105E" at the temperature of $105 \pm 1{ }^{\circ} \mathrm{C}$ till constant weight (with accuracy $\pm 0.01 \mathrm{~g}$ ) (Temminghoff \& Houba, 2004).

The measurements of colour parameters of fresh and treated cranberries were done by direct reading with the device "COLOR TEC PMC": luminance $\left(\mathrm{L}^{*}\right)$, red saturation index $\left(\mathrm{a}^{*}\right)$, and yellow saturation index $\left(b^{*}\right)$.

pH of berries was analysed by potentiometric method according to the LVS ISO 1132:2001 standard method using the Jenway $3510 \mathrm{pH}$ meter. Before determining the $\mathrm{pH}$, cranberries were homogenized with a blender.

Anthocyanin was determined by means of "Spectrophotometer anthocyanin determination method" using the Yenway 6705 UV/VIS spectrophotometer (Bordignon-Luiz, Gauche, Gris, \& Falcao, 2007).

Phenolic compounds were determined using high-performance liquid chromatography (HPLC) with UV detection at $280 \mathrm{~nm}$ (Berregi, Santos, Del Campo, \& Miranda, 2003).

The data were expressed as mean \pm standard deviation. For mathematical data processing, $p$ value at 0.05 was used to determine significant differences. The experiments were carried out in three replications.

\section{Results and Discussion}

Berries are highly perishable products needing optimum post-harvest technologies in order to maintain their storage stability and to extend their shelf life. Lower temperatures achieve a longer shelf life of berries (Mupondwa, 2009).

During our experiments it was ascertained that maximum shelf life of cranberries packaged in closed $\mathrm{PP}$ boxes at air ambiance and stored at the temperature of $3 \pm 1{ }^{\circ} \mathrm{C}$ was six months. The experiments showed that mould developed on the surface of berries stored longer than six months; therefore, such berries were not used for future experiments. The results obtained allow predicting the possible decrease in benzoic acid content, which mainly serves as a protective microbiological agent (Nohynek et al., 2006). Whereas maximum shelf-life for cranberries packaged in glass jars in water ambiance and stored at $3 \pm 1{ }^{\circ} \mathrm{C}$ was 12 months.

In the scientific literature (Özgen, Palta, \& Smith, 2002 ) it is mentioned that $0.5-\mathrm{kg}$ cranberry samples were placed into breathable plastic containers and stored, similarly to commercial storage, in a cold room maintained at about $3 \pm 1{ }^{\circ} \mathrm{C}$ with $90 \%$ relative humidity, and the shelf-life of such berries was seven weeks.

Moisture. Moisture content is the main parameter of food products that influences their storage time. It is known that shelf life of products with high moisture content is shorter than that of the products with lower moisture content. In our experiments, the moisture content decreased by $2 \%$ in cranberries stored in closed PP boxes in air ambiance for six months and in glass jars in water ambiance for 12 months, which is insignificant ( $\mathrm{p}=0.522)$.

pH. The presence of organic acids, mainly citric, malic, quinic, and benzoic acids, are responsible for the characteristically low $\mathrm{pH}$ in cranberries. These acids also aid in the stabilization and protection of anthocyanins, and help protect the much desired red color of cranberries. In theory, the $\mathrm{pH}$ should also affect the cranberry phenolic ability to inhibit lipid peroxidation and their free radical scavenging capacity (Caillet, Côté, Doyon, Sylvain, \& Lacroix, 2011a).

In cranberries packaged in closed PP boxes in air ambiance, $\mathrm{pH}$ changed $(p=0.627)$ insignificantly during storage - by $1.2 \%$ on average. Similar results were obtained in cranberries packaged in glass jars in 


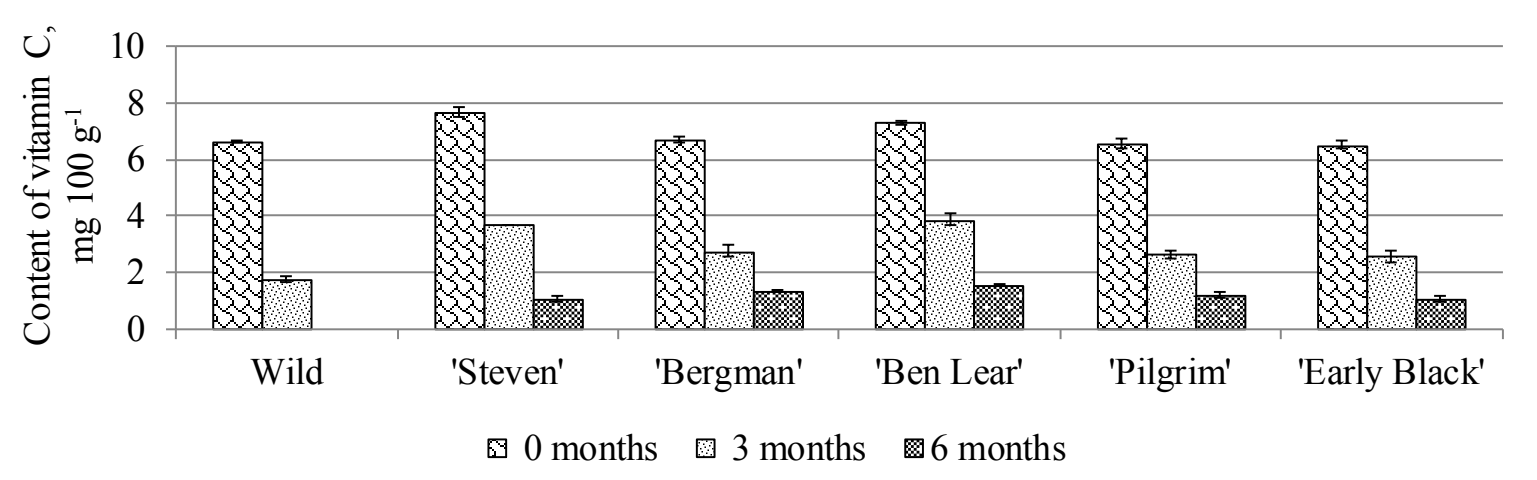

Fig. 1. Changes in vitamin $\mathrm{C}$ content in cranberries during storage in closed PP boxes.

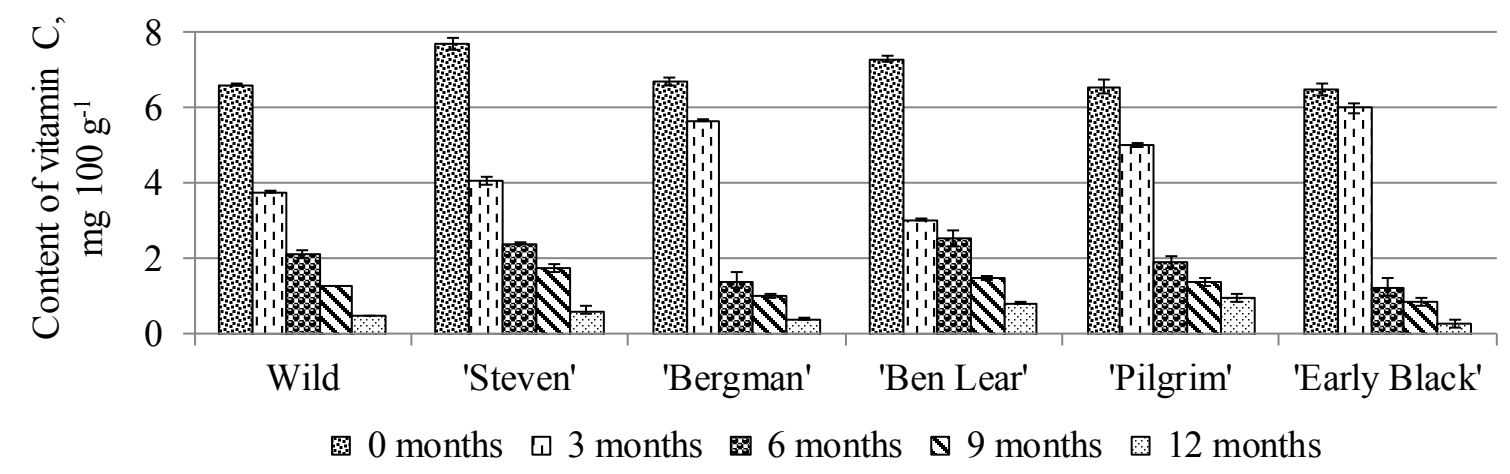

Fig. 2. Changes in vitamin $\mathrm{C}$ content in cranberries during storage in glass jars.

water ambiance: During their storage, $\mathrm{pH}$ changed by $2.3 \%$ on average, which is not significant $(p=0.061)$.

Colour. Colour is one of the most important appearance attributes of food materials, since it influences the degree of consumer acceptability or it can even be harmful to health (Wong \& Stanton, 1992).

During our experiments, insignificant changes in the $\mathrm{L}^{*}$ and $\mathrm{a}^{*}$ colour compounds were found in cranberries packaged in closed PP boxes in air ambiance and in glass jars in water ambiance ( $p=0.255$ and $p=0.387$ respectively) and stored at the temperature of $3 \pm 1{ }^{\circ} \mathrm{C}$. However, Özgen, Palta, and Smith (2002) have found that after seven weeks of cold storage of cranberries at $3 \pm 1{ }^{\circ} \mathrm{C}$, the marketable fruit among dark-red, light-red, blush and white berries were $82,74,63$, and $44 \%$ respectively. Ceponis and Stretch (1983) have observed that more colored cranberries (variety 'Early Black') had lower incidence of physiological breakdown during storage compared to less colored fruit. This was true also for fruit harvested three times during the ripening period (early, middle, and late). Both researchers recommend the more colored cranberries for cold storage (Ceponis \& Stretch, 1983).
Vitamin C. It was proved that changes in vitamin $\mathrm{C}$ in cranberries (Fig. 1) were substantial during storage in the chosen conditions; moreover, the changes were dependent on the chosen packaging conditions and the berry cultivar. Substantial decreases in vitamin $\mathrm{C}$ content were established in cranberries packaged in PP boxes in air ambiance during six months of storage, i.e., vitamin $\mathrm{C}$ content decreased by $82 \%$ in the 'Steven' and 'Early Black' cranberries compared to fresh cranberries. Whereas in other tested berry samples, vitamin $\mathrm{C}$ decreased by $80 \%$ on average, which is significant $(p=0.006)$. The shelf life of wild cranberries during storage in the above-mentioned conditions was three months, and vitamin $\mathrm{C}$ content decreased by $73 \%(p=0.004)$ compared to fresh berries (Fig. 1).

The decrease in vitamin $\mathrm{C}$ content in the cultivar 'Early Black' berries stored for 12 months in glass jars was more intensive - by $96 \%$, but in 'Pilgrim' cranberries - not so pronounced (by $85 \%$ ). After storing the cranberries for six months under the same conditions, the content of vitamin C decreased by $81 \%$ in 'Early Black' cultivar and by $65 \%$ in 'Ben Lear' compared to fresh berries (Fig. 2). Such results might be explained with a higher ascorbic acid content in 


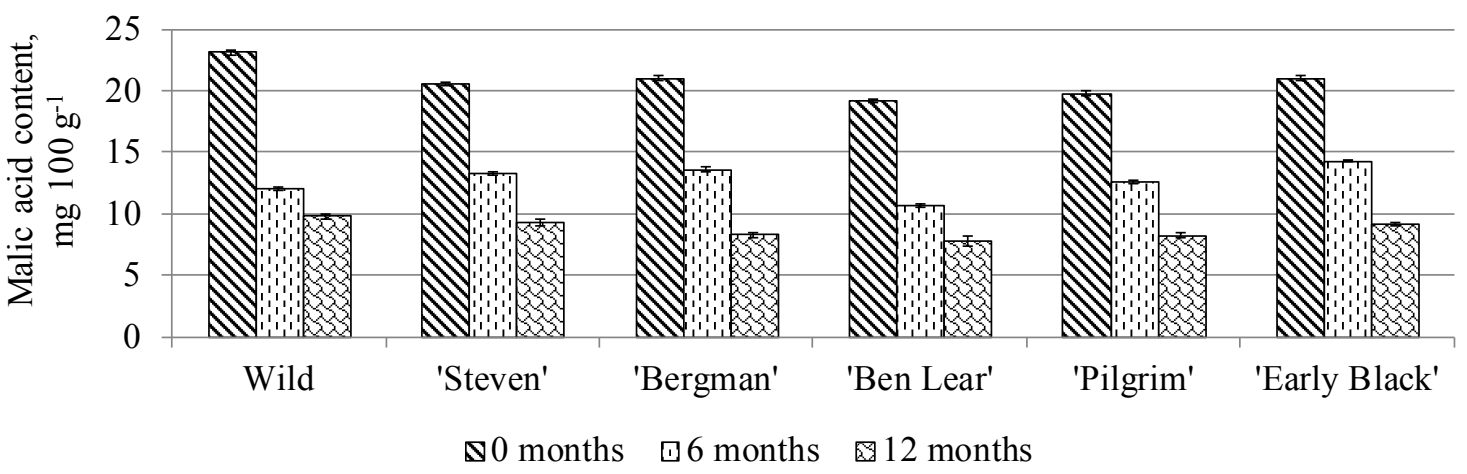

Fig. 3. Changes in malic acid content in cranberries during storage in closed PP boxes.

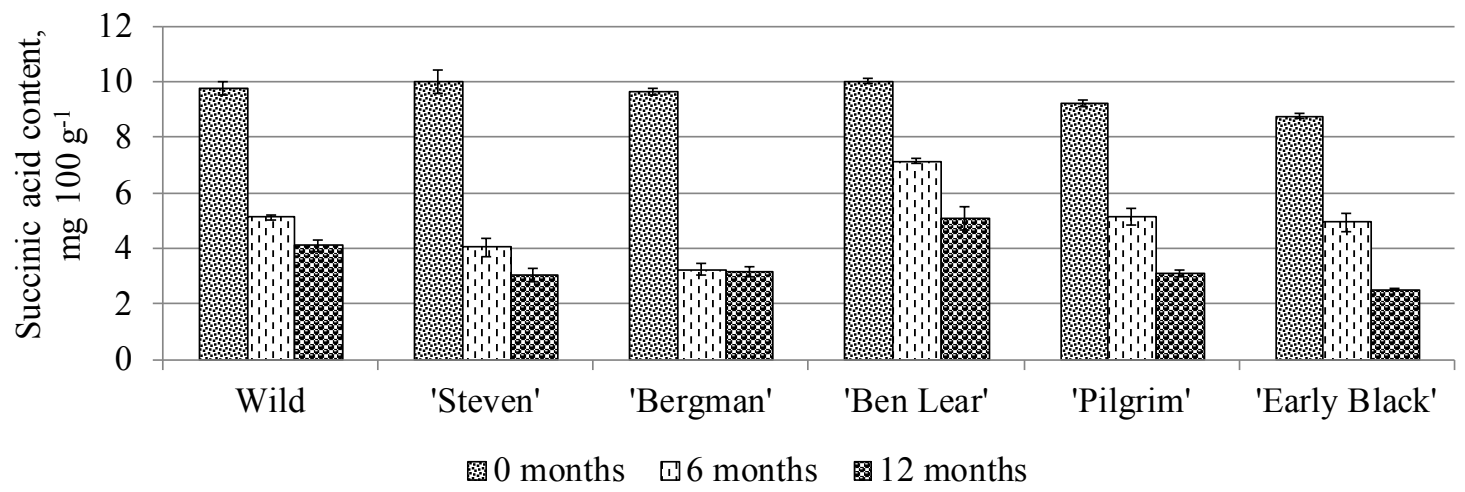

Fig. 4. Changes in succinic acid content in cranberries during storage in PP boxes.

berry cell vacuole in complex with flavonoids with a very low $\mathrm{pH}$ value, as a result of which oxidation of vitamin C occurs slower (Kalt, Forney, Martin, \& Prior, 1999).

Anthocyanin. Recent studies have shown that anthocyanins, proanthocyanidins, and phenolics from cranberries are active components in the molecular mechanism behind the various health benefits of cranberries. Cranberry proanthocyanidins have been shown to raise the Gibbs free energy of adhesion to uroepithelial cells making attachment thermodynamically unfavorable (Lacombe, Wu, Tyler, \& Edwards, 2010). In our experiment, it was established that anthocyanin content in cranberries packaged in closed PP boxes in air ambiance and in glass jars in water ambiance ( $p=0.502$ and $p=0.447$ respectively) decreased insignificantly during storage at $3 \pm 1{ }^{\circ} \mathrm{C}$, i.e., by $8.2 \%$ on average.

Özgen, Palta, \& Smith (2002) have found that differences in anthocyanin content among different ripeness stages were significant: Dark-red berries had nearly four times higher anthocyanin content than light-red berries.
Organic acids. Organic acids are important primary metabolites that contribute to berry development. The organic acids such as malic and tartaric are the most abundant compounds contributing to the berry juice sweetness and acidity respectively. Their concentrations and/or ratios vary during the berry development and maturation stages. Organic acids are produced in berries and start accumulating in the berry at early stages of berry development (Eyéghé-Bickong, Aleksandersson, Gouws, Young, \& Viiier, 2012).

In our research, we found that fresh cranberries contain higher amounts of hinic acid and malic acid but lower amounts of tartaric acid and succinic acid (Fig. 3). The content of tartaric, hinic and succinic acids significantly $(p=0.004)$ decreased in cranberries packaged in closed PP boxes in air ambiance during six months of storage, whereas changes in malic acid content were insignificant $(p=0.822)$ (Figs 3 and 4 ).

Transformation of organic acids and signs of spoilage indicate that acetic acid synthesis occurs in berries if their storage time exceeds three months. Similar results were observed in berries packaged in glass jars in water ambiance (Figs 5 and 6). 


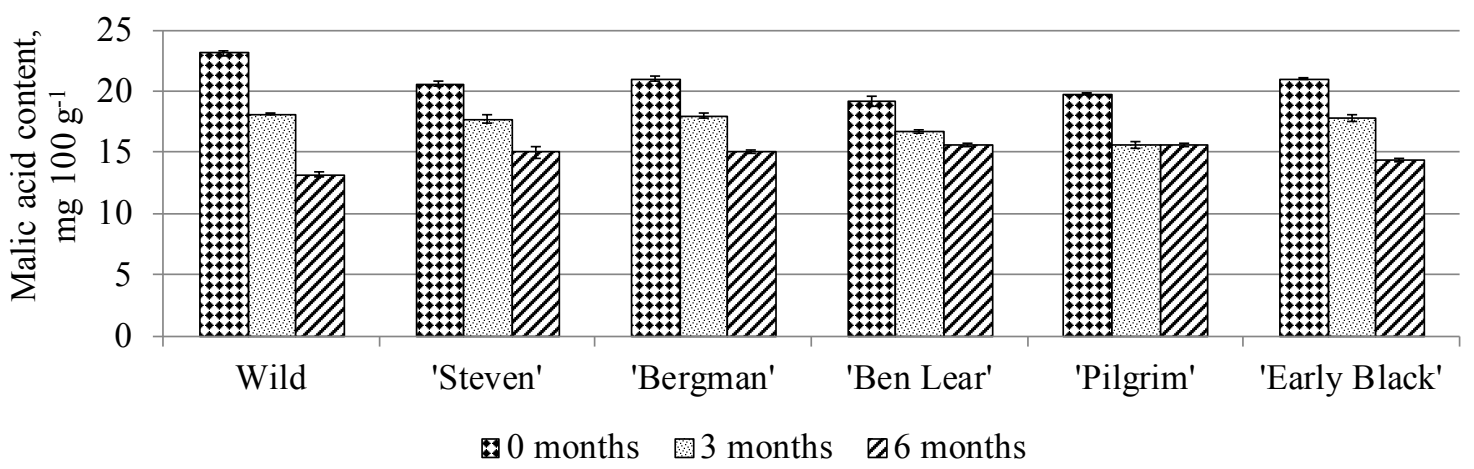

Fig. 5. Changes in malic acid content in cranberries during storage in glass jars.

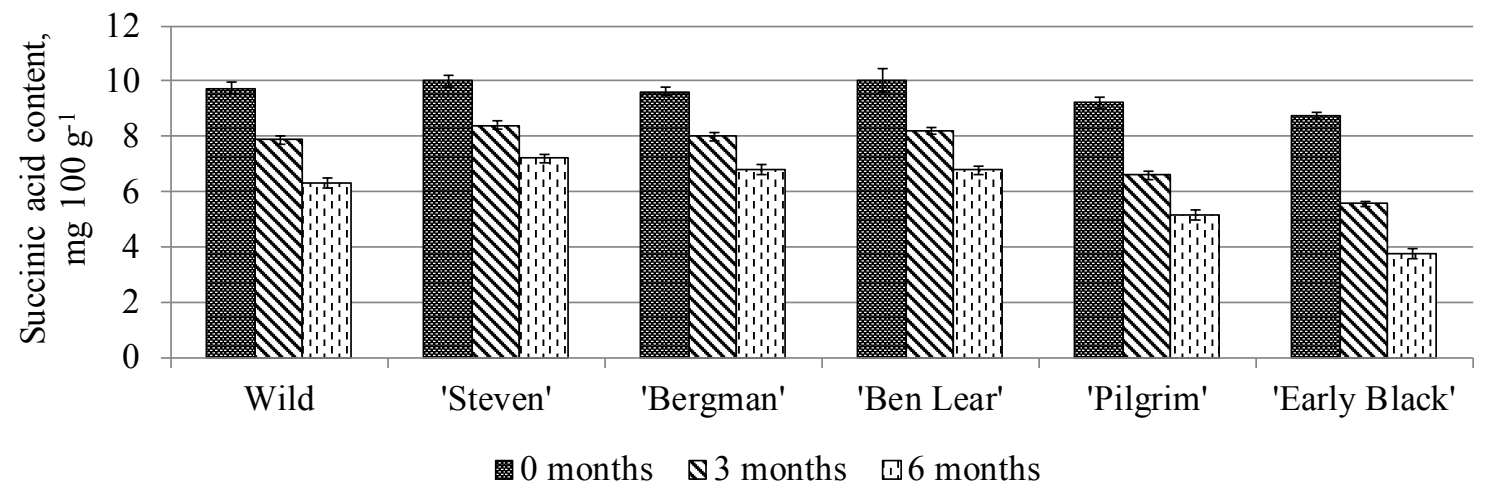

Fig. 6. Changes in succinic acid content in cranberries during storage in glass jars.

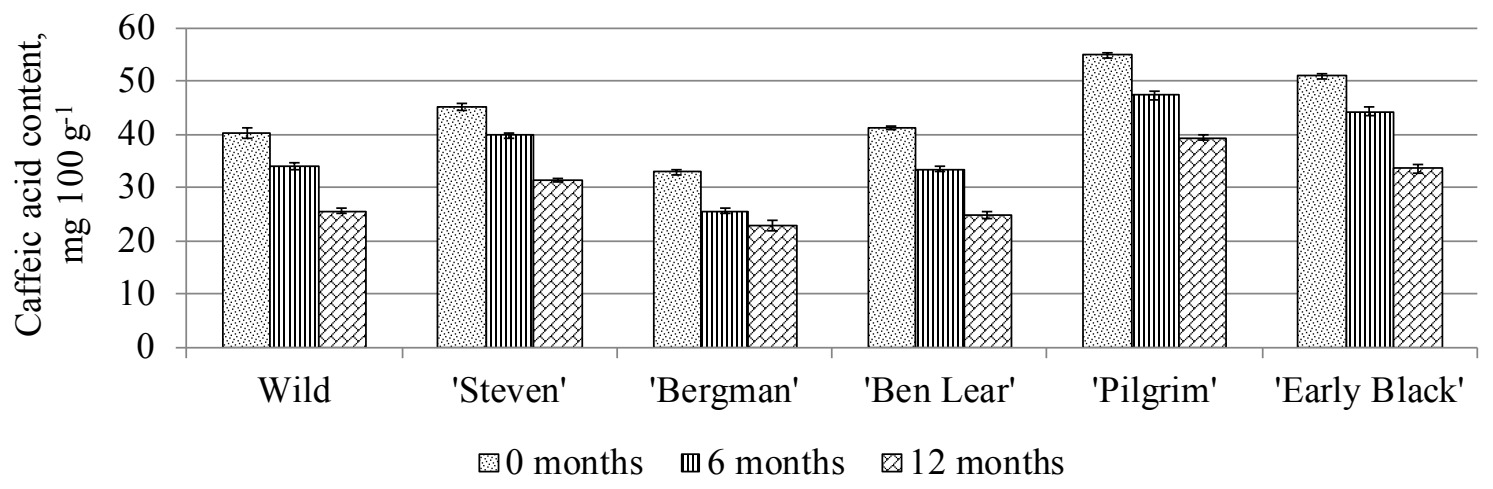

Fig. 7. Changes in caffeic acid content in cranberries during storage in closed PP boxes.

Storing berries in water ambiance for six months, the content of organic acids decreased by $43.27 \%$ on average, which was significant $(p=0.001)$; the exception was hinic acid - changes in its content were insignificant $(p=0.562)$. It can be concluded that storage time and conditions had a significant effect on the changes in organic acids content in berries $(P=95 \%)$.

Phenolic compounds. Polyphenols are proposed to protect against the damage caused by free radicals to deoxyribonucleic acid, membranes and cellular components, which are involved in disease progression. However, this theory has been challenged by the growing evidence that dietary polyphenols have significantly different bioavailability (Boath, Stewart, \& McDougall, 2012).

We found that fresh cranberries contain rutine, caffeic acid, catechine, and chlorogen acid. The content of polyphenols in berries packaged in closed PP boxes in air ambiance (Figs 7 and 8) 


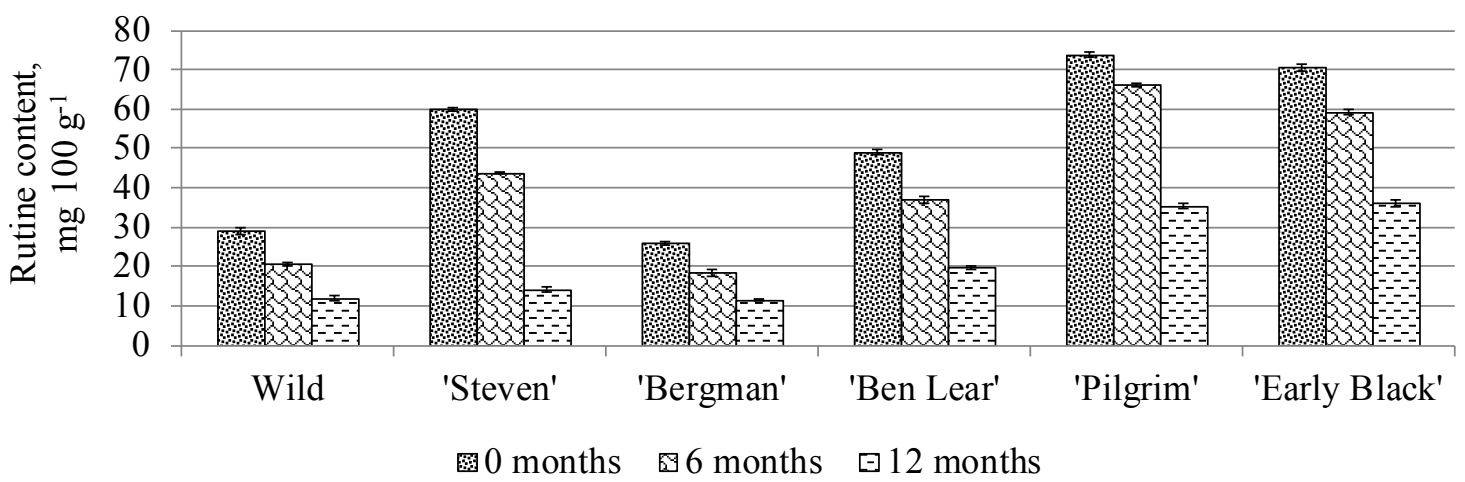

Fig. 8. Changes in rutine content in cranberries during storage in closed PP boxes.

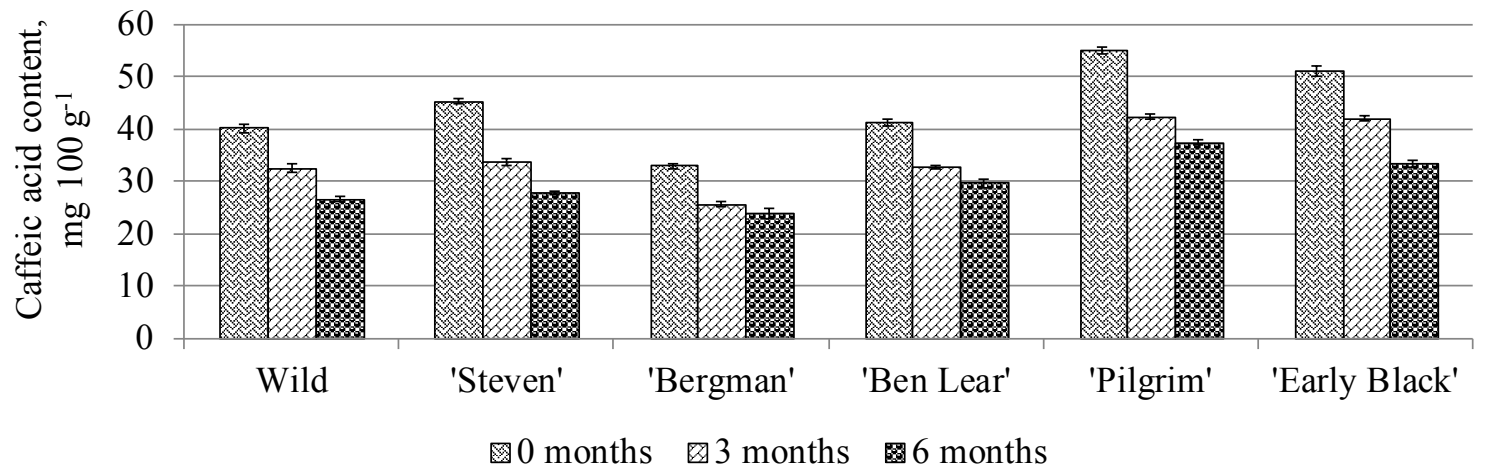

Fig. 9. Changes in caffeic acid content in cranberries during storage in glass jars.

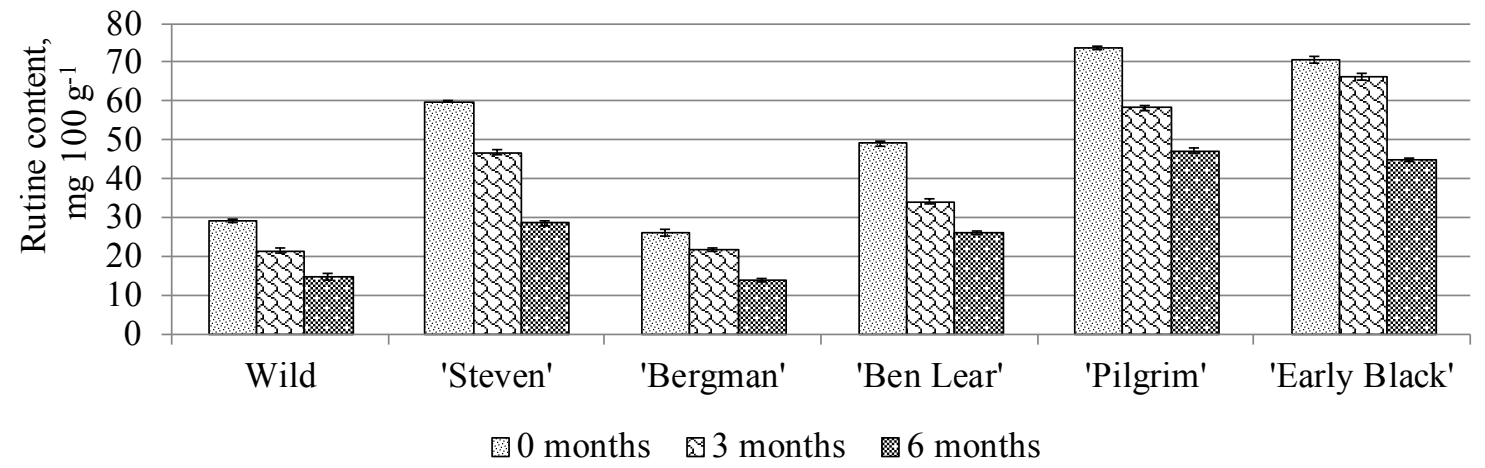

Fig. 10. Changes in rutine content in cranberries during storage in glass jars.

during six-month storage decreased on average by $47 \%$, which is significant $(p=0.003)$; in berries packaged in glass jars in water ambiance (Figs 9 and 10) during six-month storage - on average by $27 \%$, which is significant $(p=0.003)$ too, and after 12 months of storage - by $55 \%(p=0.0001)$. Those changes might have been caused by the condensation product that had developed during berry storage in closed PP boxes at $3 \pm 1{ }^{\circ} \mathrm{C}$.

Perkins-Veazie and Collins (2002) have found that in order to assure a prolonged postharvest life and to better maintain the berry quality, it is commonly recommended to pick climacteric fruits when mature but unripe or at an early ripeness stage.

\section{Conclusions}

1. The shelf-life of cranberries packaged in closed PP boxes in air ambiance and stored at the temperature of $3 \pm 1{ }^{\circ} \mathrm{C}$ was six months, whereas the maximum shelf life for cranberries packaged in glass jars in water ambiance and stored at $3 \pm 1{ }^{\circ} \mathrm{C}$ was 12 months.

2. Insignificant differences in moisture content, $\mathrm{pH}$ value, colour intensity and anthocyanin content 
were found in cranberries during storage under all selected conditions.

3. During 12-month storage in glass jars in water ambiance, vitamin $\mathrm{C}$ content in cranberries decreased on average by $90 \%$, organic acids content - by $54 \%$, and phenolic compounds content - by $60 \%$.

4. After six-month storage in closed boxes in air ambiance, vitamin $\mathrm{C}$ content in cranberries decreased on average by $99 \%$, organic acids content - by $30 \%$, and phenolic compounds content - by $34 \%$.

\section{References}

1. Ali, L., Svensson, B., Alsanius, B.W., \& Olsson, M.E. (2011). Late season harvest and storage of Rubus berries - Major antioxidant and sugar levels. J. Scientia Horticulturae, 129(3), 376-381.

2. Berregi, I., Santos, J.I., Del Campo, G., \& Miranda, J.I. (2003). Quantitative determination of (-)- epicatechin in cider apple juice by HNMR. J. Talanta, 61:2(17), 139-145.

3. Boath, A.S., Stewart, D., \& McDougall, G.J. (2012). Berry components inhibit $\alpha$-glucosidase in vitro: Synergies between acarbose and polyphenols from black currant and rowanberry. J. Food Chemistry, 135(3), 929-936.

4. Bordignon-Luiz, M.T., Gauche, C., Gris, E.F., \& Falcao, L.D. (2007). Colour stability of anthocianins from Isabel grapes (Vitis labrusca L.) in model systems. J. LWT-Food Science and Technology, 40(4), 594-599.

5. Caillet, S., Côté, J., Doyon, G., Sylvain, J.-F., \& Lacroix, M. (2011a). Antioxidant and antiradical properties of cranberry juice and extracts. J. Food Research International, 44(5), 14081413.

6. Caillet, S., Côté, J., Doyon, G., Sylvain, J.-F., \& Lacroix, M. (2011b). Effect of juice processing on the cancer chemopreventive effect of cranberry. Food Research International, 44(4), 902-910.

7. Camire, M.E., Dougherty, M.P., \& Briggs, J.L. (2007). Functionality of fruit powders in extruded corn breakfast cereals. J. Food Chemistry, 101:2(13), 765-770.

8. Ceponis, M.J., \& Stretch, A.W. (1983). Berry color, water-immersion time, rot, and physiological breakdown of cold-stored cranberry fruits. HortScience, 18, 484-485.

9. Chen, H., Zuo, Y., \& Deng, Y. (2001). Separation and determination of flavonoids and other phenolic compounds in cranberry juice by high-performance liquid chromatography. Journal of Chromatography A, 913(1-2), 387-395.

10. De Rosso, V.V., \& Mercadante, A.Z. (2007). Evaluation of colour and stability of anthocyanins from tropical fruits in an isotonic soft drink system. J. Innovative Food Science \& Emerging Technologies, 8(3), 347-352.

11. Ellingsen, I., Seljeflot, I., Arnesen, H., \& Tonstad, S. (2009). Vitamin C consumption is associated with less progression in carotid intima media thickness in elderly men: A 3-year intervention study. Nutrition, Metabolism and Cardiovascular Diseases, 19(1), 8-14.

12. Eyéghé-Bickong, H.A., Alexandersson, E.O., Gouws, L.M., Young, P.R., \& Vivier, M.A. (2012). Optimisation of an HPLC method for the simultaneous quantification of the major sugars and organic acids in grapevine berries. J. Chromatography B, 885-886:15:43-49.

13. Hendry, G.A., \& Houghton, J.D. (1996). Natural Food Colourants. Glasgow: Backie Academic and Professional.

14. Hernandez, Y., Lobo, M.G., \& Gonzalez, M. (2009). Factors affecting sample extraction in the liquid chromatographic determination of organic acids in papaya and pineapple. J. Food Chemistry, 114(2), 734-741.

15. Hoffmann, G. (2008). CIELab Color Space. Retrieved from http://www.fho-emden. de/ hoffmann/cielab03022003.pdf

16. Jackman, R.L., \& Smith, J.L. (1996). Natural Food Colourants. London, Glasgow: Chapman \& Hall.

17. Kalt, W., Forney, C.F., Martin, A., \& Prior, R.L. (1999). Antioxidant capacity, vitamin $\mathrm{C}$, phenolics, and anthocyanins after fresh storage of small fruits. J. Agric. Food Chem, 47, 4638-4644.

18. Lacombe, A., Wu, V.C.H., Tyler, S., \& Edwards, K. (2010). Antimicrobial action of the American cranberry constituents; phenolics, anthocyanins, and organic acids, against Escherichia coli O157:H7. Int. J. of Food Microbiology, 139(1-2), 102-107.

19. Mupondwa, E.K. (2009). Economic benefits of controlled atmosphere storage and modified atmosphere packaging. In E.M. Yahia (Ed.), Modified and controlled atmospheres for storage, transportation, and packaging of horticultural 
commodities (pp. 527-552). Boca Raton, FL: CRC Press.

20. Nohynek, L.J., Alakomi, H.-L., Kähkönen, M.P., Heinonen, M., Helander, I.M., OksmanCaldentey, K.-M., \& Puupponen-Pimiä, R.H. (2006). Berry phenolics: Antimicrobial properties and mechanisms of action against severe human pathogens. J. Nutrition and Cancer, 54(1), 18-32.

21. Özgen, M., Palta, J.P., \& Smith, J.D. (2002). Ripeness stage at harvest influences postharvest life of cranberry fruit: Physiological and anatomical explanations. Postharvest Biology and Technology, 24, 291-299.

22. Perkins-Veazie, P., \& Collins, J.K. (2002). Quality of erect-type blackberry fruit after short intervals of controlled atmosphere storage. Postharvest Biol. Technol., 25, 235-239.

23. Reynoso, R.O., \& Michelis, A. (1994). Parameters affecting freezing storage and transport of individually frozen Schoeneman raspberries. Int J. Refrigeration, 17, 209-213.

24. Temmingoff, E.E.J.M., \& Houba, V.J.G. (2004). Plant Analysis Procedures. Springer-Verlag New York Inc, Kluwer Academic Publisher.

25. Wong, M., \& Stanton, D.W. (1992). Effect of removal of amino acids and phenolic compounds on non-enzymatic browning in stored kiwi fruit juice concentrates. LWT - Food Science and Technology, 26, 138-144.

26. Zhao, J. (2007). Berry fruit. Taylor \& Francis Group, CRC Press.

\section{Acknowledgements}

The research and publication have been prepared within the framework of the ESF project "Formation of the research group in food science”, Contract No. 2009/0232/1DP/1.1.1.2.0/09/APIA/VIAA/122, and project "Support for LLU doctoral studies implementation", Contract No. 2009/0180/1DP/1.1.2.1.2/09/IPIA/ VIAA/017. 